\title{
Solvothermal Reactions: an original route for the synthesis of novel materials
}

\section{Gérard DEMAZEAU}

Emeritus Professor, ICMCB, CNRS, University Bordeaux 1 "Sciences and Technologies", Site de l'ENSCPB - 87 Avenue du Dr A. Schweitzer - 33608 PESSAC - Cedex (France)

\begin{abstract}
.
Twenty years after the first development of solvothermal reactions, it appears important through the last research activities to trace the future trends taking into account their potentialities and the different economical constraints.

During these last twenty years solvothermal reactions have been mainly used from preparing micro- or nanoparticles with different morphologies.

Due to the importance to dispose of new materials for developing either basic research or industrial applications, such a presentation will be only focussed on the potentialities of solvothermal reactions in materials synthesis.

Solvothermal reactions are mainly characterized by different chemical parameters (nature of the reagents and of the solvent) and thermodynamical parameters (in particular temperature, pressure).

- $\quad$ The selection of the composition of the solvent opens new research areas for stabilizing materials belonging to different classes of materials (alloys, oxides, nitrides, sulfides...).

- $\quad$ The mild temperature conditions generally used are able to improve chemical diffusion and reactivity in order to help the preparation of specific materials at the frontier between either different classes of inorganic materials (oxides-nitrides, nitrides-halides...) or inorganic/organic, inorganic/biologic frameworks.

- The high pressure conditions, due to the small conveyed energy compared to temperature, allow also to stabilize metastable frontier materials (geo-inspired or bio-inspired materials).

- $\quad$ In the future, taking into account, from one side: the economical and the environmental constraints, and from the other: the industrial demand of materials characterized by specific physical, chemical and biological properties, the potential developments of Solvothermal processes will be analyzed.
\end{abstract}




\section{Introduction}

A solvothermal process can be defined as "a chemical reaction in a closed system in the presence of a solvent (aqueous and non aqueous solution) at a temperature higher than that of the boiling point of such a solvent". Consequently a solvothermal process involves high pressures. The selected temperature (sub- or supercritical domains) depends on the required reactions for obtaining the target-material through the involved process.

In the case of aqueous solutions as solvent, the hydrothermal technology have been studied and developed a long time ago with different objectives: (i) mineral extraction (as for leaching ores [1]), (ii) investigation of the synthesis of geological materials [2,3], (iii) synthesis of novel materials [4-6] (iv) crystal growth - in particular the elaboration of $\alpha$-quartz single crystals due to its piezoelectric properties [7], (v) the deposition of thin films [8], (vi) the development of sintering processes in mild conditions [9], (vii) the elaboration of fine particles well defined in size and morphology [10].

Hydrothermal processes - due in particular to the chemical composition of water as solvent - is mainly appropriated to the preparation of hydroxides, oxihydroxides or oxides versus the temperature value. The development of non-oxide materials (in particular nitrides, chalcogenides...) for investigating their physical properties and for industrial applications required the development of new processes involving non aqueous solvents. Consequently, if solvothermal reactions is a "generic term" for a chemical reaction in a close system in presence of a solvent, these reactions are mainly developed with non aqueous solvents for preparing non-oxide materials.

During these last fourty years hydrothermal reactions have been used in Materials Chemistry $[5,11]$ or Materials Science for developing soft processing in advanced inorganic materials [12] or for preparing functional ceramics[13,14].

The interest for non -oxide materials has led to the development of solvothermal reactions either for preparing novel materials or for setting-up new processes leading to nanostructured materials $[4,15]$.

The interest of hydrothermal/solvothermal reactions in a large domain of applications (materials synthesis, crystal growth, thin films deposition, low temperature sintering...) has improved the development of new processes involving original technologies as hydrothermalelectrochemical methods [16], microwave-hydrothermal method [17]...

Chemical reactions into a solvent (aqueous or non aqueous) under high pressure and mild temperature conditions (sub- or supercritical domain of the selected solvent) appear 
promising for developing Materials Chemistry and Materials Sciences (in particular for nanotechnologies).

\section{Main parameters governing solvothermal reactions}

Two types of parameters are involved in solvothermal reactions:

$\rightarrow$ the chemical parameters,

$\rightarrow$ the thermodynamical parameters.

Table I gives the correlations between such parameters and the corresponding solvothermal reactions.

\section{II.1. Chemical parameters}

Two different parameters can be taken into account: the nature of the reagents and the nature of the solvent.

The chemical composition of the precursors must be appropriated to that of the targetmaterials. In addition, the concentration of the precursors seems to play a role on the control of the shape of nanocrystallites resulting of a solvothermal process. Q. WANG et al. [18] through the solvothermal preparation of CdSe and CeTe nanocrystals have claimed the control of the crystallites-shape (dot, rod, ...) with the concentration of the precursors. The interactions between reagents and solvent play an important role in the solvothermal reactions.

The selection of the solvent plays a key-role through the control of the chemical mechanisms leading to the target-material.

The reaction mechanisms induce, during the solvothermal reactions, are dependent on the physico-chemical properties of the solvent. For example LI et al. [19] have described the preparation of $\mathrm{Cu}_{7} \mathrm{Te}_{4}$ using $\mathrm{CuCl}_{2}, \mathrm{H}_{2} \mathrm{O}$ and tellurium as reagents and ethylenediamine as solvent. Using the same experimental conditions but changing only the nature of the solvent (benzene or diethylamine), tellurium did not react with copper chloride. Compare to non polar solvent as benzene, ethylenediamine is a polarizing solvent - such a property being able to increase the solubility of the reagents. In addition its complexing properties can play an important role in the reaction mechanisms.

The complexing properties of the solvent can lead to the intermediate formation of stable complexe systems $\left(\mathrm{M}(\mathrm{en})_{3}^{2+}\right)$. Such a complex-cation can act as a template due to its octahedral geometry and can be incorporated into the structure of the final material. This type 
of solvothermal reactions has led to the synthesis of $\mathrm{Sb}(\mathrm{III})$ and $\mathrm{Sb}(\mathrm{V})$ thioantimonates $\left[\mathrm{Mn}(\mathrm{en})_{3}\right]_{2} \mathrm{Sb}_{2} \mathrm{~S}_{5}$ and $\left[\mathrm{Ni}(\mathrm{en})_{3}(\mathrm{Hen}) \mathrm{SbS}_{4}\right.$. [20].

In some cases the formation of complex-cations is important as an intermediate step during the solvothermal reaction mechanisms. This is the case of the solvothermal preparation of the semiconductor material CuInSe $e_{2}$ [21]. The starting products were $\mathrm{CuCl}_{2}, \mathrm{InCl}_{3}$ and Se. The solvent was either ethylenediamine (en) or diethylamine. The selected experimental conditions were $180^{\circ} \mathrm{C}$ and the resulting autogeneous pressure. The propose reaction mechanisms involve four steps:

(i) $2 \mathrm{InCl}_{3}+3 \mathrm{Se}^{2-} \rightarrow \mathrm{In}_{2} \mathrm{Se}_{3}+6 \mathrm{Cl}^{-}$, (ii) $\mathrm{In}_{2} \mathrm{Se}_{3}+\mathrm{Se}^{2-} \rightarrow 2\left(\mathrm{InSe}_{2}\right)^{-}, \quad$ (iii) $\mathrm{Cu}^{+}+2 \mathrm{en} \rightarrow \mathrm{Cu}(\mathrm{en})_{2}^{+}$,

(iv) $\mathrm{Cu}(\mathrm{en})_{2}+\left(\mathrm{InSe}_{2}\right)^{-} \rightarrow \mathrm{CuInSe}_{2}+2(\mathrm{en})$.

The nucleophilic attack by amine could activate selenium to form $\mathrm{Se}^{2-}$ in a similar way that sulphur is activate by amine to $\mathrm{S}^{2-}[22,23]$. The formation of the $\mathrm{Cu}(\mathrm{en})_{2}{ }^{+}$complex $\left(\mathrm{Cu}^{+}\right.$ resulting from the in situ reduction of $\mathrm{Cu}^{2+}$ ) seems to play are important role in controlling the nucleation and growth of $\mathrm{CuInSe}_{2}$ nano-whiskers. Replacing ethylenediamine by ethylamine as solvent, the reactivity is lowered and the resulting morphology consists on spherical particles of CuInSe 2 .Consequently the nature of the solvent can act on the reactivity and the morphology of the resulting crystallites.

The physico-chemical properties of the selected solvent can also play an important role for orienting the structural form of the final material. LU et al. [24] have underlined that the solvothermal synthesis of MnS can lead to metastable ( $\beta$ and $\gamma$ ) or stable $(\alpha)$ structural forms versus the composition of the solvent. Using $\mathrm{MnCl}_{2} \cdot 4 \mathrm{H}_{2} \mathrm{O}$ and $\mathrm{SC}\left(\mathrm{NH}_{2}\right)_{2}$ as reagents and either an hydrothermal reaction (water as solvent) and or a solvothermal reaction (ethylenediamine as solvent), the stable form ( $\alpha-M n S)$ with the rocksalt structure was observed. With the same reagents but with benzene as solvent, the wurtzite type structure $(\gamma$-MnS) was prepared, with tetrahydrofurane (THF) only the zinc-blende structure ( $\beta$-MnS) can be observed.

The stabilization of different structural forms: stable $\alpha$ form or metastable forms $(\beta, \gamma)$ versus water and the two others solvents (benzene and tetrahydrofurane) can be attributed to the ability to form a stable $\mathrm{Mn}$ complex $\left(\mathrm{Mn}\left(\mathrm{H}_{2} \mathrm{O}\right)_{6}{ }^{2+}\right.$ or $\left.\mathrm{Mn}(\mathrm{en})_{3}{ }^{2+}\right)$ during the reaction mechanisms.The difference observe between benzene and THF suggests that a non polar solvent $\left(\mathrm{C}_{6} \mathrm{H}_{6}\right)$ is more appropriated for stabilizing the wurtzite-form ( $\gamma$-MnS). Consequently the solubility of the $\mathrm{Mn}^{2+}$ precursor appears to play also an important role for orienting the stabilization of a stable structural form. 
Another example is the selective synthesis of $\mathrm{KTaO}_{3}$ either as perovskite or pyrochlore structure versus the composition of the mixed solvents (water-ethanol or water-hexane systems) with a $\mathrm{KOH}$ concentration one order of magnitude lower than that in conventional processes [25].

The oxidation-reduction properties of the solvothermal medium during the reaction can be induced by the nature of the solvent or the composition of mixed solvents and by the use of additives.

The solvothermal processing of $\mathrm{Sb}(\mathrm{III}) \mathrm{Sb}(\mathrm{V}) \mathrm{O}_{4}$ nanorods from $\mathrm{Sb}_{2} \mathrm{O}_{5}$ powder involves the reducing properties of ethylenediamine as solvent. [26]. At the same temperature $\left(200^{\circ} \mathrm{C}\right)$, if the reaction time is one day only $\mathrm{Sb}(\mathrm{III}) \mathrm{Sb}(\mathrm{V}) \mathrm{O} 4$ nanorods are formed but after 3 days only metallic Sb particles are observed.

The formation of copper(I) chloride particles with tetrapod-like-morphology used a mixture of acetylacetone and ethylene-glycol as solvent (50/50) and $\mathrm{CuCl}_{2} \cdot 2 \mathrm{H}_{2} \mathrm{O}$ as precursor. During the solvothermal processing of such particles acetylacetone acts as reducing agent $\left(\mathrm{Cu}^{2+} \rightarrow \mathrm{Cu}^{+}\right)$whereas ethylene-glycol favorizes the anisotropic shape for $\mathrm{CuCl}$ crystallites. [27].

On the contrary the solvothermal preparation of InAs as nanoscale semiconductor from $\mathrm{InCl}_{3}$ and $\mathrm{AsCl}_{3}$ as reagents and xylene as solvent requires the use of $\mathrm{Zn}$ metal particles as additive. The reaction mechanisms could be described as a co-reduction route: $\operatorname{In}^{3+} \rightarrow \operatorname{In}^{0}$ and $\mathrm{As}^{3+} \rightarrow \mathrm{As}^{0}$, through the reaction: $\mathrm{InCl}_{3}+\mathrm{AsCl}_{3}+3 \mathrm{Zn} \rightarrow \mathrm{InAs}+3 \mathrm{ZnCl} \mathrm{Cl}_{2}$ [28].

Another interesting illustration of the use of reducing agent in addition of the reagents involves the preparation of the mixed-valent spinel $\mathrm{CuCr}_{2} \mathrm{Se}_{4}$ which is metallic and ferromagnet with a Curie temperature of 450K [29]. RAMESHA and SESHADRI [30] have developed a solvothermal route for preparing this spinel using copper (II) acetylacetonate, chromium (III) acetylacetonate and Se powder as precursors. The additive was $\beta$-sitosterol ( $\beta$-sitosterol through an aromatization process being able to transform Se powder to $\mathrm{H}_{2} \mathrm{Se}$ ).

Additive can be use also for orienting a specific morphology for the resulting crystallites. The preparation of the new layered compound $\mathrm{Rb}_{2} \mathrm{Hg}_{3} \mathrm{Te}_{4}$ through a solvothermal reaction can illustrate such a chemical route. The reagents $\mathrm{Rb}_{2} \mathrm{Te}, \mathrm{Hg}_{2} \mathrm{Cl}_{2}$ and $\mathrm{Te}$ are mixed into ethylenediamine as solvent. Oxido-reducing reactions are involved during the solvothermal process: $\mathrm{Hg}_{2}^{2+} \rightarrow 2 \mathrm{Hg}^{2+}+2 \mathrm{e}^{-}$and $\mathrm{Te}+2 \mathrm{e}^{-} \rightarrow \mathrm{Te}^{2-}$. Then the reaction, with the 
precursor $\mathrm{Rb}_{2} \mathrm{Te}$, leads to the synthesis of $\mathrm{Rb}_{2} \mathrm{Hg}_{3} \mathrm{Te}_{4}$. The use of $\mathrm{FeCl}_{2}$ as additive was found to be essential in the crystal growing process of $\mathrm{Rb}_{2} \mathrm{Hg}_{3} \mathrm{Te}_{4}$ [31].

\section{II.2 The thermodynamical parameters.}

These parameters are: temperature, pressure and the reaction time. The solvothermal reactions are mainly developed in mild temperature conditions : $\left(\mathrm{T}<400^{\circ} \mathrm{C}\right)$.Temperature and pressure improving in the major cases the solubility, the increase of such parameters induces an enhancement of the precursors-concentration into the solvent and then favors the growing process (in particular in the preparation of micro- or nanocrystallites).

The brief analysis of the main factors governing solvothermal reactions underlines that the nature of the selected solvent plays a key-role, in particular for controlling the chemical mechanisms involved in the solvothermal reactions.

\section{Development of solvothermal reactions}

\section{III.1. Reactions involved in solvothermal processes}

Solvothermal reactions involve "in situ” different reaction-types as mentioned through the analysis of the chemical factors governing such processes. In particular, it is possible in a first approach to classify the reactions in approximately 5 types:

(i) oxidation-reduction, (ii) hydrolysis, (iii) thermolysis, (iv) complex-formation, (v) metathesis reactions.

The development of these different reactions implies to control carefully the chemistry in nonaqueous solvents and consequently to get more informations concerning the physicochemical properties of such solvents.

\section{III.2. Main applications of solvothermal processes}

Solvothermal reactions have been developed in different scientific domains:

$\rightarrow$ the synthesis of novel materials (design of materials with specific structures and properties),

$\rightarrow$ the processing of functional materials (an emerging route in synthesis chemistry),

$\rightarrow$ the crystal growth at low-temperature (a way to single crystals of low-temperature forms or with à low density of defects), 
$\rightarrow$ the preparation of micro- or nanocrystallites well define in size and morphology (as precursors of fine structured ceramics ,catalyst ,elements of nano-devices...),

$\rightarrow$ the low- temperature sintering (preparation of ceramics from metastable structural forms ,low temperature forms or amorphous materials),

$\rightarrow$ the thin films deposition ( with the development of low-temperature processes)

Such a paper being devoted to the development of solvothermal reactions in Materials Chemistry a specific attention will be given to the synthesis of novel materials and the development of new processes.

\section{Solvothermal synthesis of novel materials}

R. ROY has described the challenge for synthesizing new materials to specification [32]. Hydro-and solvothermal technologies being able to bring some new synthesis routes in mild conditions [33], such a synthesis routes appear promising for developing functional materials.

\section{IV.1. Geo-inspired materials}

The structure of natural materials can be a source of inspiration for the conception of novel materials. Phyllosilicates is a large class of geomaterials characterized by layered structures. In most cases $\mathrm{OH}$ groups participate to such structures and consequently are a limitation of the thermal stability due to the reaction: $2 \mathrm{OH}^{-} \rightarrow \mathrm{H}_{2} \mathrm{O}^{\lambda}$ vapor $+\mathrm{O}^{2-}+\square$ (anionic vacancies). When the concentration of anionic vacancies increases the structure is decomposed. In order to impede such a phenomenon, the objective was to prepare a new class of layered oxides free of $\mathrm{OH}$ groups but always isostructural of the natural phyllosilicates. Due to the charge difference between $\mathrm{OH}^{-}$et $\mathrm{O}^{2-}$ a cationic substitution must be initiated: $\mathrm{M}^{2+} \rightarrow \mathrm{M}^{3+}$ or $\mathrm{M}^{3+} \rightarrow \mathrm{M}^{4+}$ (in $\mathrm{O}_{\mathrm{h}}$ and or $\mathrm{T}_{\mathrm{d}}$ sites) (Fig. 1)

A two-steps process has been developed. The first consisted on a sol-gel process [using as precursors $\mathrm{Si}\left(\mathrm{OC}_{2} \mathrm{H}_{5}\right)_{4}, \mathrm{Al}\left(\mathrm{OC}_{4} \mathrm{Hg}\right)_{3}, \mathrm{Mg}\left(\mathrm{OC}_{2} \mathrm{H}_{5}\right)_{2}$ and $\left.\mathrm{KOCH}_{3}\right]$. The second was a solvothermal treatment of the resulting gel $\left(50<\mathrm{P}<100 \mathrm{MPa}, 650<\mathrm{T}<750^{\circ} \mathrm{C}\right)$ using the 2methoxy-ethanol as solvent (Table II). The resulting material with the composition $\mathrm{K}\left(\mathrm{Mg}_{2} \mathrm{Al}\right) \mathrm{Si}_{4} \mathrm{O}_{12}$ is isostructural to the mica-phlogopite $\mathrm{KMg}_{3}\left(\mathrm{Si}_{3} \mathrm{Al}\right) \mathrm{O}_{10}(\mathrm{OH})_{2}$. Such a new layered oxide (called phyllosiloxide) has been characterized through different techniques (XRD, TEM, RMN...) and has been tested as an interphase in ceramic-matrix composite (Fig. 2) [34,35]. 
Solvothermal processes open the route to a novel class of bidimensional oxides derived from natural phyllosilicates.

\section{IV.2. Materials with light elements}

Such a class of materials presents a strong interest, the strong chemical bonding inducing specific physico-chemical properties as hardnest, insulating, optical... In the main cases the weak reactivity of the precursors requires for the synthesis severe pressure and temperature conditions.

Due to the enhancement of the reactivity observed for solvothermal reactions, during these last thirty fifty years, such processes were investigated for preparing in particular: diamant, c-BN and $\mathrm{C}_{3} \mathrm{~N}_{4}$.

\section{IV.2.1. Hydrothermal synthesis of diamond}

Due to its large variety of physico chemical properties, diamond has, during these last fifty years, required a great attention for developing new synthesis routes in mild temperaturepressure conditions.

The conventional route industrially developed for preparing diamond involved a flux-assisted conversion from graphite as reagent and a metallic flux as solvent YAMADA et al. [36] have underlined the role of water in the " $\mathrm{Mg}_{2} \mathrm{SiO}_{4}$-graphite" system in the diamond formation under high temperatures-high pressures conditions. The flux-assisted conversion route using metallic systems as solvents requiring severe $\mathrm{P}, \mathrm{T}$ conditions and being probably different than the natural process developed in the crust of the earth, many researchers have tried to reproduce the nucleation and the growth of natural diamonds. Different routes have been explored: (i) the decomposition of minerals [37], (ii) the investigation of different systems involving transition metal-carbon or carbide and water as Ni-NaOH-C, Ni-C- $\mathrm{H}_{2} \mathrm{O}, \mathrm{SiC}-\mathrm{H}_{2} \mathrm{O}$ [38-40], (iii) the hydrothermal decomposition of Chlorinated hydrocarbon. Recently KORABLOV et al. reported that diamond structured carbon has been synthesized at $300^{\circ} \mathrm{C}$ and $1 \mathrm{GPa}$ using as reagents: 1, 1, 1-trichloroethane and $10 \mathrm{M} \mathrm{NaOH}$ solution as solvent in the presence of hydrogenated natural diamond or c-BN seeds [41]. In this hydrothermal approach the temperature and pressure conditions $\left(140 \mathrm{MPa}-800^{\circ} \mathrm{C}\right)$ for diamond deposition appear a promising route. In addition diamond being metastable in such conditions, supercritical water under high pressures seems to play an important role. Such solvothermal processes must be re-investigated through the selection of reagents and solvents able to promote carbon diffusion and deposition. 


\section{IV.2.2. Solvothermal preparation of cubic boron nitride (c-BN)}

c-BN, due to the position of $\mathrm{B}$ and $\mathrm{N}$ in the Periodic Table adopts the same structures than diamond. c-BN was firstly prepared by WENTORF [42] through a flux assisted conversion process using h-BN as precursor. During these last twenty years through different approaches (thermodynamical calculations, c-BN P, T stability...) several equilibrium curves (h-BN/c-BN) have been proposed by SOLOZHENKO et al. [43] and MAKI and FUKUNAGA et al. [44] (Fig. 3). The main characteristic of these curves is the intersection with the axis of temperature suggesting that c-BN could be thermodynamically stable at normal pressure conditions.

Two different approaches have been developed during these last 10 years in order to prepare, through a solvothermal process c-BN in mild pressure and temperature conditions: (a) the use of nitriding solvent for the flux-assisted conversion h-BN $\rightarrow$ c-BN, (b) the development of metathesis reactions and a non polar solvent. Through the first approach ,hydrazine $\mathrm{NH}_{2} \mathrm{NH}_{2}$ has been developed as solvent for studying in such solvothermal conditions the h-BN $\rightarrow \mathrm{c}-\mathrm{BN}$ conversion in presence of $\mathrm{Li}_{3} \mathrm{~N}$ as additive[45]. Figure 4 gives a schematic view of the curves h-BN/c-BN underlining the synthesis $\mathrm{P}, \mathrm{T}$ conditions of c-BN. The mildest $\mathrm{P}, \mathrm{T}$ conditions leading to the preparation of c-BN were $1.7 \mathrm{GPa}$ and $500^{\circ} \mathrm{C}$.

During these last five years different solvothermal reactions have been investigated using benzene as solvent and a metathesis reaction between boron halogenides and a nitride. Using $\mathrm{BBr}_{3}$ and $\mathrm{Li}_{3} \mathrm{~N}$ as reagents the influence of the temperature has been studied [46,47]. At low temperature, h-BN is predominant and the c-BN formation is improved at increasing temperature $\left(\mathrm{T}<480^{\circ} \mathrm{C}, \mathrm{P}=\right.$ autogeneous pressure). The influence of the chemical composition of the boron chalcogenide has been also investigated [48]. In the same $\mathrm{P}, \mathrm{T}$ conditions (autogeneous pressure, $250^{\circ} \mathrm{C}$ ) with $\mathrm{Li}_{3} \mathrm{~N}$ and benzene as solvent, h-BN is the dominant phase for $\mathrm{BBr}_{3}$ as reagent and $\mathrm{c}-\mathrm{BN}$ in the case of $\mathrm{BCl}_{3}$. In parallel the influence of the induction effect (using nano-crystallites of $\mathrm{GaP}$ isostructural of c-BN as seeds and $\mathrm{BBr}_{3}+\mathrm{Li}_{3} \mathrm{~N}$ as precursors and benzene as solvent with the same $\mathrm{P}, \mathrm{T}$ conditions) has been underlined. The cubic phase is predominant whereas without such seeds only the h-BN formation is observed [49].Different solvothermal processes has been tested with different nitride reagents as $\mathrm{NaN}_{3}$ [50] or different solvents as aqueous solutions [51].

The c-BN synthesis through a solvothermal process appears an important challenge not only for improving the knowledge of its thermodynamical stability but also for industrial 
developments, c-BN being not only a superhard material but also the first III-V compounds able to improve applications in electronics and optoelectronics.

\section{IV.2.3. Solvothermal elaboration of $\mathrm{C}_{3} \mathrm{~N}_{4}$}

The prediction of the stability of carbon-nitride as $\mathrm{C}_{3} \mathrm{~N}_{4}$ through ab-initio calculations [52] has largely improved a strong interest for such a material through different physicochemical approaches (CVD, PVD, high pressures...). In addition through ab-initio calculations TETER and HEMLEY [53] have predicted five structural forms for $\mathrm{C}_{3} \mathrm{~N}_{4}$. One derived from the 2D graphitic structure and four with 3D dimensional network (two derived from the $\alpha$ and $\beta$ forms of $\mathrm{Si}_{3} \mathrm{~N}_{4}$, one from the zinc-blende structure and a new-one isostructural of the high pressure form of $\mathrm{Zn}_{2} \mathrm{SiO}_{4}$ ) (Fig. 5).

Solvothermal reactions have been investigated for the $\mathrm{C}_{3} \mathrm{~N}_{4}$ synthesis. The first consisted on the condensation of melamine (2-4-6-triamino-1-3-5 triazine) (1) and cyanuric chloride (2-4-6 trichloro-1-3-5 triazine) (2) in mild conditions (130MPa, $250^{\circ} \mathrm{C}$ ) using triethylamine $\left(\mathrm{Et}_{3} \mathrm{~N}\right)$ as a weak nucleophilic solvent for trapping the by product $\mathrm{HCl}$ [54].The resulting material was the graphitic $\mathrm{C}_{3} \mathrm{~N}_{4}$ form. A second route involving the thermolysis of melamine $\mathrm{C}_{3} \mathrm{~N}_{6} \mathrm{H}_{6}$ at high pressure $(2.5-3 \mathrm{GPa})$ in the temperature range $\left(800-850^{\circ} \mathrm{C}\right)$ using $\mathrm{NH}_{2} \mathrm{NH}_{2}$ as solvent was investigated. In such a process g- $\mathrm{C}_{3} \mathrm{~N}_{4}$ was obtained $[55,56]$.

More recently different solvothermal routes based on metathesis reactions have been investigated: (i) the reaction of $\mathrm{CCl}_{4}$ and $\mathrm{NH}_{4} \mathrm{Cl}$ at $400^{\circ} \mathrm{C}$ and autogeneous pressure [57] leading to the graphitic $\mathrm{C}_{3} \mathrm{~N}_{4}$, (ii) the liquid-solid reaction between anhydrous $\mathrm{C}_{3} \mathrm{~N}_{3} \mathrm{Cl}_{3}$ and $\mathrm{Li}_{3} \mathrm{~N}$ using benzene as solvent $\left(355^{\circ} \mathrm{C}, 5-6 \mathrm{MPa}\right)$ where the formation of the $\alpha$ and $\beta$ forms have been claimed [58].

A recent review paper gives an analysis of the potentialities of solvothermal reactions for preparing carbonitrides as bulk - material [59].

Solvothermal reactions appear a promising route to the synthesis of materials with light elements due to the strong interest of such materials for industrial applications. The improvement of the reactivity into supercritical solvents is able to lead to new industrial processes in mild temperature-pressure conditions. 


\section{IV.3 Hybrid materials between inorganic and organic chemistry and stabilization of new structures}

Due to the soft temperature conditions used for solvothermal-reactions, it is possible to stabilize hybrid materials characterize by inorganic skeleton with the participation of organic molecules; the objective of such materials being to incorporate the functionality of both components.In the main cases, such hybrid materials are characterized by original open frameworks.

Among the different synthesis ways able to lead through solvothermal reactions to hybrid-materials, two have been mainly investigated: (i) the use of specific templates, (ii) the biphasic solvothermal synthesis.

As an example the new one dimensional fluorinated nickel phosphate $\mathrm{Ni}\left(\mathrm{HP}_{2} \mathrm{O}_{7}\right) \mathrm{F} . \mathrm{C}_{2} \mathrm{~N}_{2} \mathrm{H}_{10}$ has been prepared solvothermally using ethylenediamine as the template [60].

The new copper adipate $\left[\mathrm{Cu}\left(\mathrm{C}_{6} \mathrm{H}_{8} \mathrm{O}_{4}\right)_{3}\left(\mathrm{H}_{2} \mathrm{O}\right)_{2}\left(\mathrm{C}_{6} \mathrm{H}_{11} \mathrm{OH}\right)\right]$ was obtained using a biphasic solvothermal reaction [61]. Such a synthesis is based in the solubility difference of inorganic reagents and organic reagents in two different solvents (respectively: water and alcohol as 1pentanol or cyclohexanol).

The designing and synthesizing of novel compounds with microporous structure are of important interest for their potential development in different fields: molecular sieves, ionexchange, catalysis and separation [62-66].

Consequently solvothermal reactions were strongly developed for preparing novel hybrid materials with open framework. Different families of microporous structures have been prepared through a solvothermal process as - in particular: aluminophosphates [67-69], zinc phosphates [70,71], organically intercalled oxides [72,73] or chalcogeno-metallates [74-78].

\section{Development of new processes for preparing functional nanocrystallites.}

During these last fifteen years two important features have driven research activities:

- the investigation of non-oxide systems for potential physical properties,

- the development of nanotechnologies and the study of the correlations at this nanoscale between size-morphology- and physical properties.

With the decrease of the crystallite size, sequential energy levels in semiconductors appears into discrete ones similar to those of molecules. This behaviour - called quantum confinement - induces a great change of their physico-chemical properties $[79,80]$ opening the route to new applications. 
In addition during the past fifteen years the research of specific nanostructures - in particular one-dimensional - as nanotubes [81-84], nanorods [85,86] and nanowires [87-90] has been developed.

In parallel strong efforts have received considerable attention in order to understand the specific physical properties on such nanostructures in particular electronic [91], magnetic [92], optical [93].

The potentialities of solvothermal reactions for preparing nanostructures well characterized in size, morphology and architecture have been strongly investigated in different materials families as oxides halogenides, chalcogenides, nitrides, carbides, phosphides, metallics and intermetallics...

Considering nanostructured oxides, solvothermal processes were investigated for developing potential industrial applications.As examples it is possible to quote the preparation of barium titane powders for fine dielectric ceramics [94], $\mathrm{TiO}_{2}, \alpha-\mathrm{Fe}_{2} \mathrm{O}_{3}$ and $\mathrm{La}_{1-\mathrm{x}} \mathrm{A}_{\mathrm{x}} \mathrm{MnO}_{3}$ $\left(\mathrm{A}=\mathrm{Ca}, \mathrm{Sr}, \mathrm{Ba}\right.$ ) as pigment or catalyst [95-97], $\mathrm{Li}_{1-\mathrm{x}} \mathrm{Mn}_{2} \mathrm{O}_{4-\mathrm{y}}$ or $\gamma-\mathrm{LiV}_{2} \mathrm{O}_{5}$ as electrode for lithium batteries [98,99], $\mathrm{PbCrO}_{4}$ and 1D manganese oxide for optical applications [100,101], $\mathrm{ZnO}$ due to its promising optical, electrical and piezoelectric properties [102].

Solvothermal reactions have been strongly developed for preparing nanostructured chalcogenides - in particular sulfides or tellurides - due to their large domain of applications (for example $\mathrm{Cu}_{2} \mathrm{SnS}_{3}$ [103], $\mathrm{ZnS}$ [104], $\mathrm{Fe}_{1-\mathrm{x}} \mathrm{S}$ [105], AInSe ${ }_{2}(\mathrm{~A}=\mathrm{Na}, \mathrm{K})$ [106], CdS [107109], NiS [110], SnS [111].

Different fluorides have been also synthesized as $\mathrm{KM}^{2+} \mathrm{F}_{3}$ with $\mathrm{M}=\mathrm{Mg}$, $\mathrm{Zn}$ [112] or $\mathrm{M}=\mathrm{Ni}[113]$.

Nitride- in particular III-V materials as nanoparticles - have hold a strong interest due to the potential applications of such materials: InN [114], GaN [115], AlN [116]. Some others nitrides have been also investigated as $\mathrm{CrN}$ [117], VN [118], $\mathrm{Cu}_{3} \mathrm{~N}$ [119], $\mathrm{ZrN}$ [120].

Different nano-materials as Carbides: $\mathrm{Mo}_{2} \mathrm{C}$ [121], $\mathrm{B}_{4} \mathrm{C}$ [122,123], phosphides: $\mathrm{Co}_{2} \mathrm{P}$, $\mathrm{Ni}_{2} \mathrm{P}, \mathrm{Cu}_{3} \mathrm{P}$ [124] or $\mathrm{TiP}$ [125], boride: $\mathrm{TiB}_{2}$ [126] have been also investigated using solvothermal processes.

Solvothermal synthesis of nanocrystallites with the nanotube-morphology have been developed during these last years -in particular carbon nanotubes [127-130], bismuth nanotubes [131], tellurium nanotubes [132] due to the potential applications of such specific morphology. In parallel intermetallic nano-particles as FePt nanowires have been investigated [133]. 
Solvothermal reactions appear also promising for the stabilization of novel molecular clusters [134].

\section{CONCLUSION}

Solvothermal reactions appears to be important for either the synthesis of novel materials , the preparation of nanostructured particles for nanotechnologies or the elaboration of bio-inspired materials for applications in Biosciences[135]. Due to the large variety of solvents or mixed-solvents able to be used and the different induced reactions-types versus the nature of the reagents and the chemical composition of the solvent, solvothermal processes will be important for developing original industrial processes in mild temperature and pressure conditions as for example the transformation of biomass as a renewable organic resource[136]. Nevertheless such a development will require an improvement of the knowledge of the physico-chemical properties of non-aqueous solvents under pressure and temperature conditions.

\section{References}

[1] F. HABASHI, Hydrometallurgy. 79 (2005) 15.

[2] R.W. GORANSON, Am. J. Sci. 22 (1931) 481.

[3] M. HOSAKA, Progress in crystal growth and Characterizations of Materials 21 (1991) 71.

[4] G. DEMAZEAU, J. Mater. Chem. 9 (1999) 15.

[5] S. FENG and R. XU Acc. Chem. Res. 34 (2001) 239.

[6] L.N. DEMIANETS, Prog. Crystal Growt and Charact. 21 (1990) 299.

[7] A. RABENAU and H. RAU, Philips Tech. Rev. 30 (1969) 89.

[8] Y.G. GOGOTSI and M. YOSHIMURA, Nature 367 (1994) 628.

[9] N. YAMASAKI, K. YANAGISAWA, M. NISHIOKA and S. NAKAHARA, J. Mater.Sci. Lett. 5 (1986) 355.

[10] M. RAJAMATHI and R. SESHADRI, Current Opinion in Solid State Mater. Sci. 6 (2002) 337.

[11] A. RABENAU, Angew. Chem. Int. Ed. Engl. 24 (1985) 1026.

[12] M. YOSHIMURA, J. Mater. Res. 13 (1998) 796.

[13] R.E. RIMAN, N.L. SUCHANEK and M.M. LENCKA, Ann. Chim. Sci. Mat. 27 (2002) 15. 
[14] "Handbook of Hydrothermal Technology” Edited by K. BYRAPPA, M. YOSHIMURA, Williams Andrews, LLC/Noyes Publications Park-Ridge, NJ (2000)

[15] S.H. YU, J. Ceram. Soc. Japan 109 (2001) 565.

[16] M. YOSHIMURA and W. SUCHANEK, Solid State Ionics 98 (1997) 197.

[17] S. KOMARNENI, R. ROY and Q.H. LI, Mater. Res. Bull. 27 (1992) 1393.

[18] Q. WANG, D. PAN, S. JIANG, X. JI, L. AN and B. JIANG, J. Crystal Growth 286 (2006) 83.

[19] B. LI, Y. XIE, J.X. HUANG, H.L. SU and Y.T. QIAN, J. Solid State Chemistry 146 (1999) 47.

[20] D.J. JIA, Y. ZHANG, J. DAI, Q.Y. ZHU and X.M. GU, J. Solid State Chem. 177 (2004) 2476.

[21] B. LI, Y. XIE, H. HUANG and Y. QIAN, Adv. Mater. 11 (1999) 1456.

[22] T. HAMA, T. IHARA and H. SATO, Sol. Energy Mater. 23 (1991) 380.

[23] A. ZUNGER, S. WAGNER and P.M. PETROFF, J. Electron. Mater. 22 (1993) 1.

[24] J. LU, P. QI, Y. PENG, Z. MENG, Z. YANG, W. YU and Y. QIAN, Chem. Mater. 13 (2001) 2169.

[25] Y.HE ,Y. ZHU ,N. WU ,J. Solid State Chem.177 (2004) 2985.

[26] T. JI, M. TANG, L. GUO, X. QI, Q. YANG and H. XU, Solid State Comm. 133 (2005) 765.

[27] Q. LI, M. SHAO, G. YU, J. WU, F. LI and Y. QIAN, J. Mater. Chem. 13 (2003) 424.

[28] Y.D. LI, X.F. DUAN, Y.T. QIAN, L. YANG, M.R. JI and C.W. LI, J. Am. Chem. Soc. 119 (1999) 7869.

[29] F.K. LOTGERING, Solid State Comm. 2 (1964) 55.

[30] K. RAMESHA and R. SESHADRI, Solid State Sciences 6 (2004) 841.

[31] J. LI, Z. CHEN, K.C. LAM, S. MULLEY and D.M. PROSERPIO, Inorg. Chem. 36 (1997) 684.

[32] R. ROY, Solid State Ionics, 32-33 (1989) 3.

[33] R. ROY, J. Solid State Chem. 111 (1994) 11.

[34] P. REIG, G. DEMAZEAU and R. NASLAIN, Eur. J. Solid State Inorg. Chem. 32 (1995) 439.

[35] P. REIG, G. DEMAZEAU and R. NASLAIN, J. Mater. Sci. 32 (1997) 4189.

[36] H. YAMADA, M. AKAISHI ands. YAMAOKA - International Conference on High Pressure Science and Technology (Joint AIRAPT 16-HPCJ-38 Conference -Kyoto Japan august 25-29 1997. Booklet of abstracts p.35) 
[37] A. SZYMANSKI, E. ABGAROWICZ, A. BARON, A. NIEDBALSKA, R. SALACINSKI and J. JENTEK, Diamond Relat. Mater. 4 (1995) 234.

[38] M. KOMATH, K.A. CHERIAN, S.K. KULKARNI and A. RAY, Diamond Relat. Mater. 4 (1995) 20.

[39] X.Z. ZHAO, R. ROY, K.A. CHERIAN and A. BADZIAN, Nature 385 (1997) 513.

[40] R. ROY, D. RAVICHANDRAN, A. BADZIAN and E. BREVAL, Diamond Relat. Mater. 5 (1996) 973.

[41] S. KORABLOV, K. YOKOSAWA, D. KORABLOV, K. TOHJI, N. YAMASAKI, Materials Letters 60 (2006) 3041.

[42] R.H. WENTORF Jr., J. Chem. Phys. 34 (1961) 809.

[43] V. SOLOZHENKO, Zh. Fiz. Klum. 62 (1988) 3145.

[44] J. MAKI ,H. IKAWA ,O. FUKUNAGA “New Diamond Science and Technology” Edited by R. Messier, J.T. Glass ,J.R. Butler, R. Roy ,MRS (1991) p.1051.

[45] G. DEMAZEAU, V. GONNET, V. SOLOZHENKO, B. TANGUYand H. MONTIGAUD, C.R. Acad. Sc. 320 (IIb) (1995) 419.

[46] X.P. HAO et al. Chemistry of Materials. 13 (2001) 2457.

[47] X.P. HAO et al. J. Crystal Growth. 241 (2002) 124.

[48] S. DONG, X. HAO, X. XU, D. CUI and M. JIANG, Mater. Lett. 58 (2004) 2791.

[49] X. XAO, X. XU and M. JIANG, J. Crystal Growth. 270 (2004) 192.

[50] L. CHEN, Y. GU, Z. LI, Y. QIAN, Z. YANG and J. MA, J. Crystal growth 273 (2005) 646.

[51] M. YU, K. LI, Z. LAI, D. CUI, X. HAO, M. JIANG and Q. WANG, J. Crystal growth 269 (2004) 570.

[52] M.L. COHEN, Phil. Trans. Soc. London, A 334 (1991) 01.

[53] D.M. TETER and R.J. HEMLEY, Science, 271 (1996) 53.

[54] H. MONTIGAUD, B. TANGUY, G. DEMAZEAU, S. COURJAULT, M. BIROT and J. DUNOGUES, C. R. Acad. Sci. Paris, Série IIb. 325 (1995) 229

[55] H. MONTIGAUD, B. TANGUY, G. DEMAZEAU, I. ALVES, M. BIROT and J. DUNOGUES, Diamond Relat. Mater. 8 (1999) 1707.

[56] H. MONTIGAUD, B. TANGUY, G. DEMAZEAU, I. ALVES and S. COURJAULT, J. Mater. Sci. 35 (2000) 2547.

[57] Y.J. BAI, B. LU, Z.G. LIU, L. LI, D.L. CUI, X.G. XU and Q.L. WANG, J. Crystal Growth 547 (2003) 505.

[58] Q. LU, C. CAO and C. LI, J. Mater. Chem. 13 (2003) 1241. 
[59] G. GOGLIO, D. FOY, G. DEMAZEAU, Materials Science and Engineering R (in press).

[60] Y. LIU, L. ZHANG, Z. SHI, H. YUAN and W. PANG, J. Solid State Chem. 158 (2001) 68.

[61] P.M. FORSTER, P.M. THOMAS and A.K. GHEETAM, Chem. Mater. 14 (2002) 17.

[62] A.K. CHEETHAM, G. FEREY and T. LOISEAU, Angew. Chem. Int. Ed. Engl. 39 (1999) 3268.

[63] Z. SHI, S. FENG, L. ZHANG, G. YANG and J. HUA, Chem. Mater. 12 (2000) 2930.

[64] A. CLEARFIELD, Chem. Mater. 10 (1998) 2801.

[65] S.S. CHUI, Y.S.M.F. LO, J.P.H. CHARMANT, A.G. ORPEN and I.D. WILLAMS, Science 283 (1999) 1148.

[66] S.R. BATTEN and R. ROBSON, Angew Chem. Int. Ed. Eng. 37 (1998) 1460.

[67] B. WEI, G. ZHU, J. YU, S. QIU, F.S. XIAO and O. TERASAKI, Chem. Mater. 11 (1999) 3417.

[68] L. PENG, J. LI, J. YU, G. LI, Q. FANG and R. XU, C.R. Chimie. À completer

[69] E. MEDINA, M. IGLESIAS, E. GUTIERREZ-PUEBLA and M. ANGELES MONGE, J. Mater. Chem. 14 (2004) 845.

[70] S. MANDAL, G. KAVITHA, C. NARAYANA and S. NATARAJAN, J. Solid State Chem. 177 (2004) 2198.

[71] W. FU, Z. SHI, G. LI, D. ZHANG, W. DONG, X. CHEN and S. FENG Solid State Sciences 6 (2004) 225.

[72] SAARMA, A. RAMANAN and M. JANSEN, Solid State Ionics, 170 (2004) 93.

[73] S.T. LUTTA, N.A. CHERNOUA, P.Y. ZAVALIJ and M.S. WHITTINGHAM, J. Mater. Chem. 13 (2003) 1424.

[74] G.L. SCHIMECK and J.W. KOLIS, Chem. Mater. 9 (1997) 2776.

[75] J. LI, Z. CHEN, R.J. WANG and D.M. PROSERPIO, Coordination Chemistry Reviews, 190-192 (1999) 707.

[76] Z. CHEN, R.J. WANG, X.Y. HUANG and J. LI, Acta Cryst. C 56 (2000) 1100.

[77] D.X. JIA, Y.Z. ZHANG, J. DAI, Q.Y. ZHU and X.M. GU, J. Solid State Chem. 177 (2004) 2476.

[78] D.X. JIA, J. DAI, Q.Y. ZHU, L.H. CAO and H.H. LIN, J. Solid State Chem. 178 (2005) 874.

[79] M.G. BAWENDI, M.L. STEIGERWALD and L.E. BRUS, Anni. Phys. Chem. 41 (1990) 477. 
[80] H. WELLER, Angew. Chem. Int. Ed. Engl. 32 (1993) 41.

[81] S. IIJIMA, Nature 354 (1991) 56.

[82] J.T. HU, T.W. ODOM and C.M. LIEBER, Acc. Chem. Res. 32 (1999) 435.

[83] W.K. HSU, B.H. CHANG, Y.Q. ZHU, W.Q. HAN, M. TERRONES, N. GROBERT, A.K. CHEETHAM, H.W. KROTO and D.R. WALTON, J. Am. Chem. Soc. 122 (2000) 10155.

[84] W.J. LIANG, M. BOCKRATH, D. BOZOVIC, J.H. HAFNER, M. TINKHAM and H. PARK, Nature 41 (2001) 665.

[85] V.F. PUNTES, K.M. KRISHNAN and A.P. ALIVISATOS, Science 291 (2001) 2115.

[86] X.G. PENG, L. MANNA, W.D. YANG, J. WICKHAM, E. SCHER, A.

KADAVANICH and A.P. ALIVISTOS Nature 404 (2000) 59.

[87] K.P. JOHNSTIN, R.C. DOTY and B.A. KORGEL, Science 287 (2000) 1471.

[88] M.S. GUDIKSEN and I.M. LIEBER, J. Am. Chem. Soc. 122 (2000) 8801.

[89] Y. LEI, L.D. ZHANG and J.C. FAN, Chem. Phys. Lett. 338 (2001) 231.

[90] M.H. HUANG, Y. WU, H. FEICK, N. TRAN, E. WEBER and P. YANG, Adv. Mater. 13 (2001) 113.

[91] T.W. ODOM, J.L. HUANG, P. KIM and C.M. LIEBER J. Phys. Chem. B. 104 (2000) 2794.

[92] T. THURN-ALBRECHT, J. SCHOTTER, C.A. MASTLE, N. EMLEY, T. SHIBAUCHI, L. KRUSIN-ELBAUM, K. GUARINI, C.T. BLACK, M.T. TUOMINEN and T.P. RUSSELL, Science 290 (2000) 2126.

[93] X.F. DUAN, Y. HUANG, Y. CUI, J. WANG and C.M. LIEBER, Nature 409 (2001) 6816.

[94] J.F. BOCQUET, K. CHHOR and C. POMMIER, Mater. Chem. Phys. 57 (1999) 273.

[95] C. WANG, Z.X. DENG, G. ZHANG, S. FAN and Y. LI, Powder Technol. 125, 39-44 (2002),

[96] D. CHEN, X. JIAO, D. CHEN, Mat. Res. Bull. 36 (2001) 1057.

[97] C. VASQUEZ-VASQUEZ, M.A. LOPEZ-QUINTELA, J. Solid State Chem. 179 (2006) 3229.

[98] W.J. LI, E.W. SHI, Z.Z. CHEN, Y.Q. ZHEN and Z.W. YIN, J. Solid State Chem. 163 (2002) 132.

[99] Y.W. WANG, H.Y. XU, H. WANG, Y.C. ZHANG, Z.Q. SONG, H. YAN and C.R. WAN, Solid State Ionics 167 (2004) 419. 
[100]G. ZHOU, M. LÜ, F. GU, S. WANG, Z. XIU and X. CHENG, J. Crystal Growth 270 (2004) 283.

[101]O.P. FERREIRA, L. OTUBO, R. ROMANO and O.L. ALVES, Crystal Growth \& Design, 6 (2006) 601.

[102]A.L. PAN, R.B. LIU, S.Q. WANG, Z.Y. WU, L. CAO, S.S. XIE and B.S. ZOU, J. Crystal Growth 282 (2005) 125.

[103]B. LI, Y. XIE, J. HUANG and Y. QIAN, J. Solid State Chem. 153 (2000) 170.

[104]C. MA, D. MOORE, J. LI and Z.L. WANG, Adv. Mater. 15 (2003) 228.

[105]M. NATH, A. CHOUDHURY, A. KUNDU and C.N. R. RAO, Adv. Mater. 15 (2003) 2098.

[106]R.B. ZHENG, J.H. ZENG, M.S. MO and Y.T. QIAN, Mater. Chem. Phys. 82 (2003) 116.

[107]U.K. GAUTAM, R. SESHADRI and C.N.R. RAO, Chem. Phys. Lett. 375 (2003) 560.

[108]A. VADIVEL-MURUGAN, R.S. SONOWANE, B.B. KALE, S.K. APTE and A.V. KULKARNI, Mater. Chem. Phys. 71 (2001) 98.

[109]F.H. ZHAO, Q. SU, N.S. XU, C.R. DING, M.M. WU, J. Mater. Sci. 41 (2006) 1449.

[110]Z. MENG, Y. PENG, L. Xu and Y. QIAN, Mat. Lett. 53 (2002) 165.

[111]S.K. PANDA, S. GORAI, S. CHAUDHURI, Materials Science and Engineering B 129 (2006) 265.

[112]R. HUA, Z. JIA, D. XIE and C. SHI, Mat. Res. Bull. 37 (2002) 1189.

[113]M. ZHANG, Z. WANG, M. MO, X. CHEN, R. ZHANG, W. YU and Y. QIAN, Mater. Chem. Phys. 89 (2005) 373.

[114]Y.J. BAI, Z.G. LIU, X.G. XU, D.L. CUI, X.P. HAO, X. FENG and Q.L. WANG, J. Crystal Growth. 241 (2002) 189.

[115]K. SARDAR and C.N.R. RAO, Adv. Mater. 16 (2004) 425.

[116]L. LI, X. HAO, N. YU, D. CUI, X. XU and M. JIANG, J. Crystal Growth, 258 (2003) 268.

[117]X.F. QIAN, X.M. ZHANG, C. WANG, K.B. TANG, Y. XIE and Y.T. QIAN, Mat. Res. Bull. 34 (1999) 433.

[118]P. CAI, Z. YANG, C. WANG, P. XIA, Y. QIAN, Materials Letters. 60 (2006) 410.

[119]J. CHOI, E.G. GILLAN, Inorg. Chem. 126 (2005) 5372.

[120]Y. GU, F. GUO, Y. QIAN, H. ZHENG and Z. YANG, Mat. Lett. 57 (2003) 1679.

[121]Y. GU, Z. LI, L. CHEN, Y. YING and Y. QIAN, Mat. Res. Bull. 38 (2003) 1119. 
[122]L. SHI, Y. GU, L. CHEN, Y. QIAN, Z. YANG and J. MA, Solid State Comm. 128 (2003) 5.

[123] Y. GU, L. CHEN, Y. QIAN, W. ZHANG and J. MA, J. Amer. Ceram. Soc. 88 (2005) 225.

[124]Y. XIE, H.L. SU, X.F. QIAN, X.M. LIU and Y.T. QIAN, J. Solid State Chem. 149 (2000) 88.

[125]Y. GU, L. CHEN, Y. QIAN and H. GU, J. Mater. Sci. Lett. 22 (2003) 1463.

[126]Y. GU, Y. QIAN, L. CHEN and F. ZHOU, J. Alloys Compounds. 352 (2003) 325.

[127]G. HU, M. CHENG, D. MA and X. BAO, Chem. Mater. 15 (2003) 1470.

[128]W. WANG, S. KUNNAR, J.Y. HUANG, D.Z. WANG and Z.F. REN, Nanotechnology. 16 (2005) 21.

[129]H. YANG, P. MERCIER, S.C. WANG and D.L. AKINS, Chem. Phys. Lett. 416 (2005) 18.

[130]B. BASAVALINGU, K. BYRAPPA, M. YOSHIMURA, P. MADHUSUDAN and A.S. DAYANANDA, J. Mater. Sci. 41 (2006) 1465.

[131]X.Y. LIU, J.H. ZENG, S.Y. ZHANG, R.B. ZHENG, X.M. LIU and Y.T. QIAN, Chem. Phys. Lett. 374 (2003) 348.

[132]G. WEI, Y. DENG, Y.H. LIN and C.W. NAN, Chem. Phys. Lett. 372 (2003) 590.

[133] Y. HOU, H. KONDOH, R. CHE, M. TAKEGUCHI, T. OHTA, Small 2 (2006) 235.

[134]R.H. LAYE, E.J.L. McINNES, Eur. J. Inorg. Chem. (2004) 2811.

[135]C. SANCHEZ, H. ARRIBART and M.M. GUILLE, Nat. Mater. 4 (2005) 277.

[136]T. MIYAZAWA, S.OHTSU, Y. NAKAGAWA and T.FUNAZUKURI, J.Mater. Sci.41 (2006) 1489. 
Table Captions

Table I Main factors governing solvothermal processes.

Table II Comparison of two preparation processes tested for stabilizing phyllosiloxides from a sol $\rightarrow$ gel starting step.

Figure Captions

Fig. 1 Schematic structure and composition of a phyllosiloxide $\left(\mathrm{KMg}_{2} \mathrm{AlSi}_{4} \mathrm{O}_{12}\right)$ (b) through cationic substitutions in the mica-phlogopite lattice $\left(\mathrm{KMg}_{3} \mathrm{AlSi}_{3} \mathrm{O}_{10}(\mathrm{OH})_{2}\right](\mathrm{a})$.

Fig. 2 Physico-chemical characterizations of the phyllosiloxide $\mathrm{K}\left(\mathrm{Mg}_{2} \mathrm{Al}\right) \mathrm{Si}_{4} \mathrm{O}_{12}$.

Fig. 3 Equilibrium c-BN/h-BN curves according to MAKI et al. [44] et SOLOZHENKO [43] compared to that derived from the diamond/graphite curve.

Fig. 4 H.P. domain concerning the c-BN synthesis using a solvothermal process (h-BN as reagent, $\mathrm{NH}_{2} \mathrm{NH}_{2}$ as solvent and $\mathrm{Li}_{3} \mathrm{~N}$ as additive) [45].

Fig. 5 Prediction of different structural forms adopted by $\mathrm{C}_{3} \mathrm{~N}_{4}$ [53]. 
Chemical factors - nature of the solvent $\rightarrow$ versus

Chemical composition

- selected precursor(s) depending on $\leftrightarrow$ Reaction mechanisms

- mixing chemical method

Thermodynamical factors

- temperature

- pressure

Correlated to the reaction

mechanisms

(subcritical or super critical domain)

Table I 


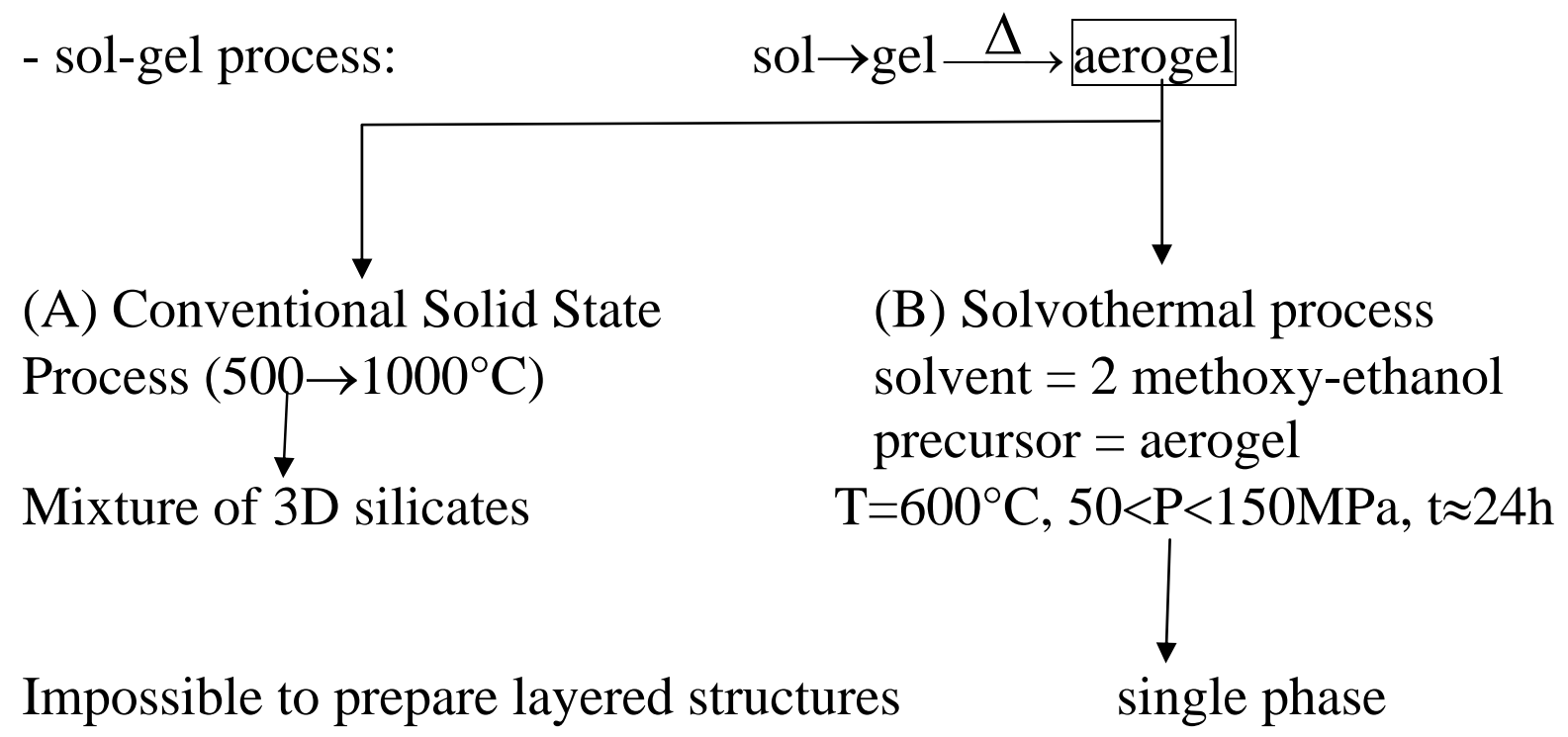

Table II 
$6 \mathrm{O}^{2-}$

$2 \mathrm{~K}^{+}$

$6 \mathrm{O}^{2-}$

$3 \mathrm{Si}^{4+}+1 \mathrm{Al}^{3+}$

$4 \mathrm{O}^{2-}+2 \mathrm{OH}^{-}$

$6 \mathrm{Mg}^{2+}$

$4 \mathrm{O}^{2-}+2 \mathrm{OH}^{-}$

$3 \mathrm{Si}^{4+}+1 \mathrm{Al}^{3+}$

$6 \mathrm{O}^{2-}$

$2 \mathrm{~K}^{+}$

$6 \mathrm{O}^{2-}$

$\mathrm{KMg}_{3} \mathrm{AlSi}_{3} \mathrm{O}_{10}(\mathrm{OH})_{2}$

$\mathrm{KMg}_{3} \mathrm{AlSi}_{3} \mathrm{O}_{10}(\mathrm{OH})_{2}$

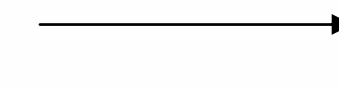

$6 \mathrm{O}^{2-}$

$2 \mathrm{~K}^{+}$

$6 \mathrm{O}^{2-}$

$4 \mathrm{Si}^{4+}$

$6 \mathrm{O}^{2-}$

$4 \mathrm{Mg}^{2+}+2 \mathrm{Al}^{3+}$

$6 \mathrm{O}^{2-}$

$4 \mathrm{Si}^{4+}$

$6 \mathrm{O}^{2-}$

$2 \mathrm{~K}^{+}$

$6 \mathrm{O}^{2-}$

Fig. 1 


\section{I.R. Spectroscopy}
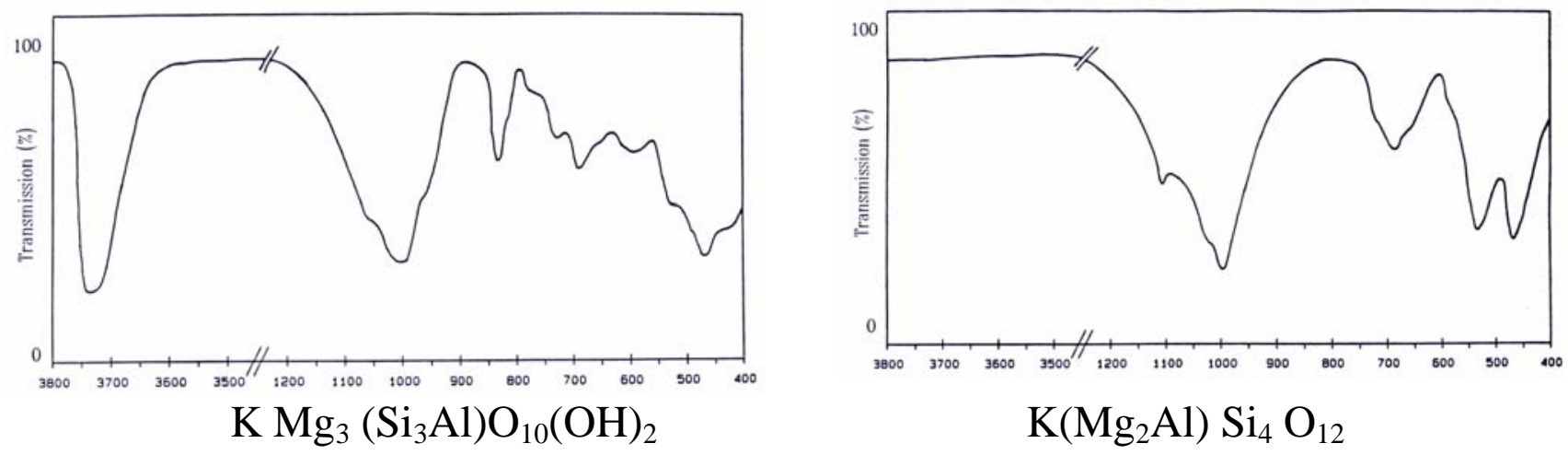

X.Ray Diffraction

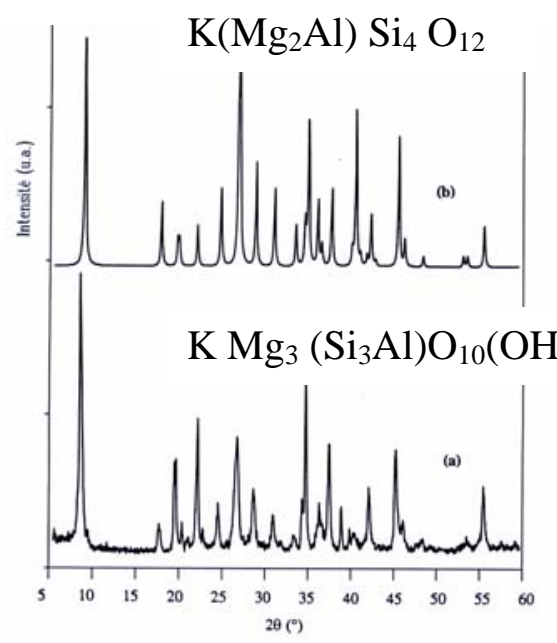

Scanning Electron Microscopy

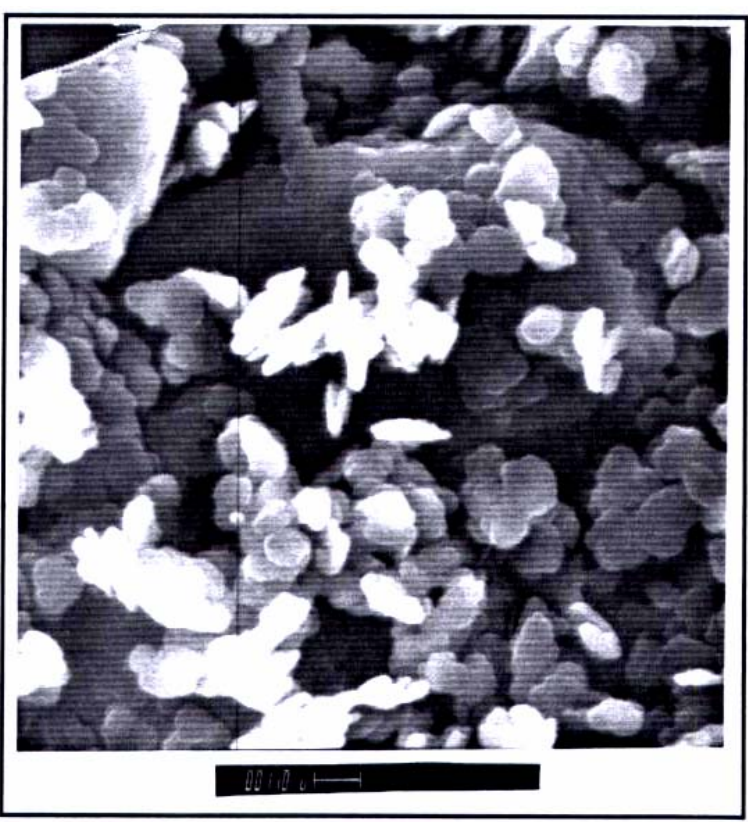

H.R.T.M.

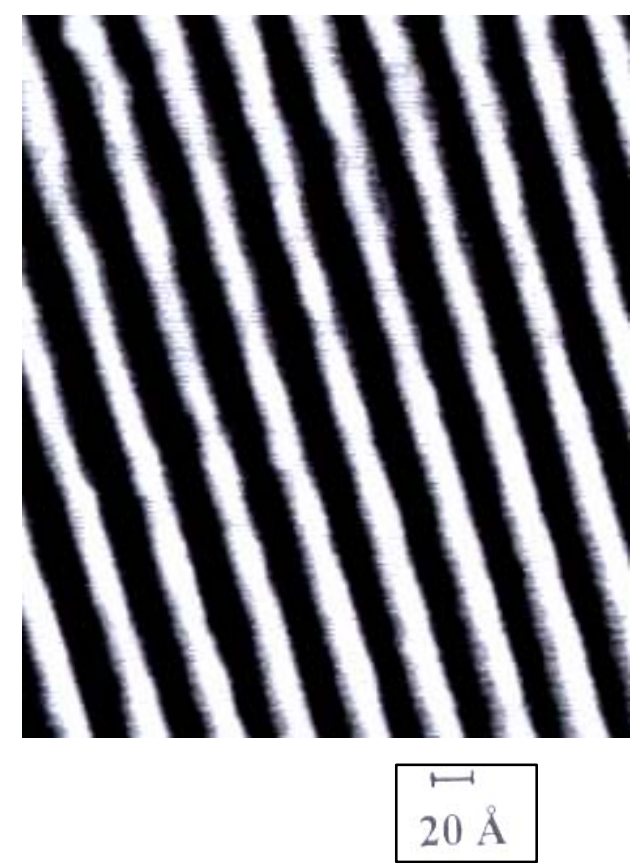

Fig. 2 


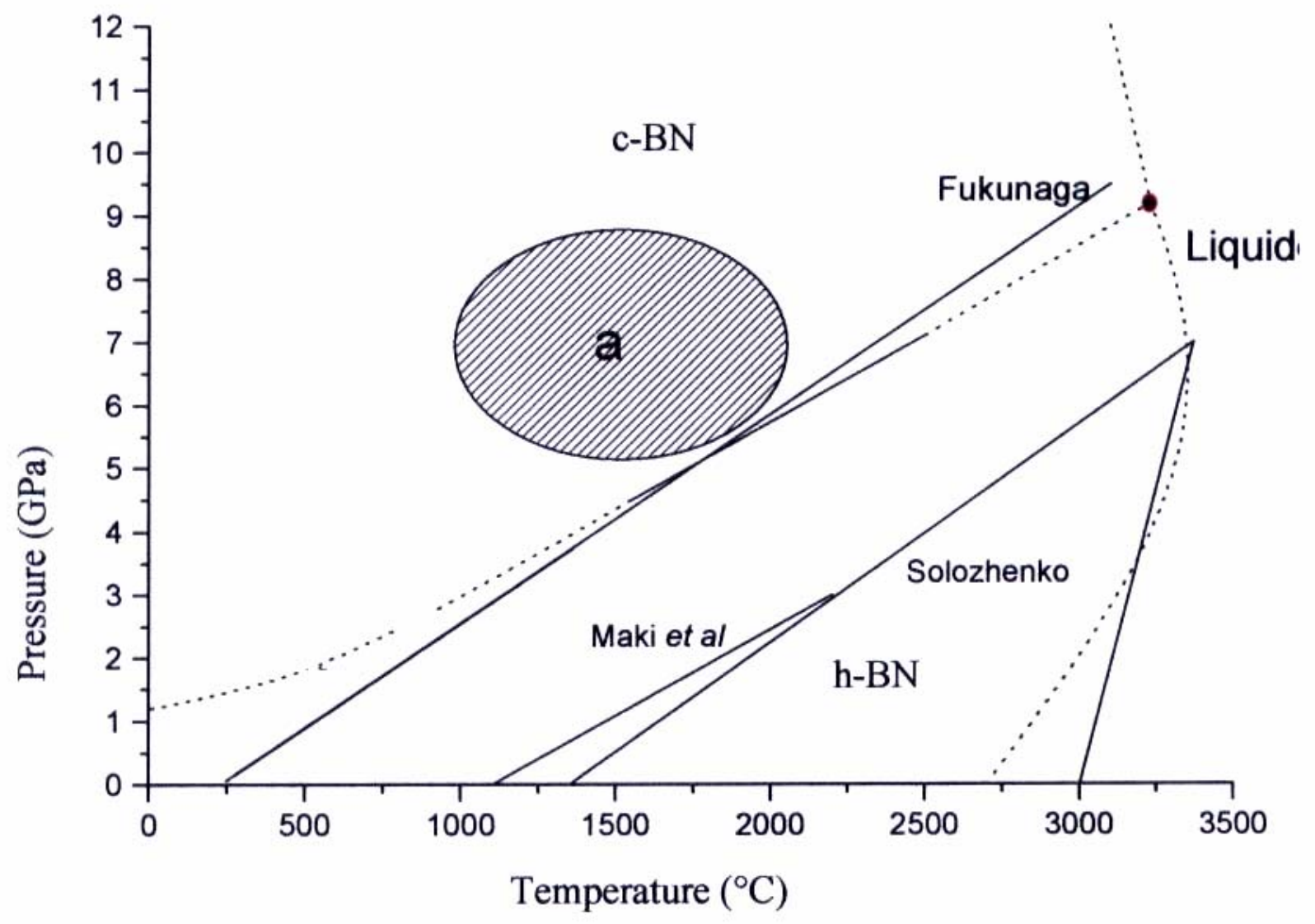

Fig. 3 


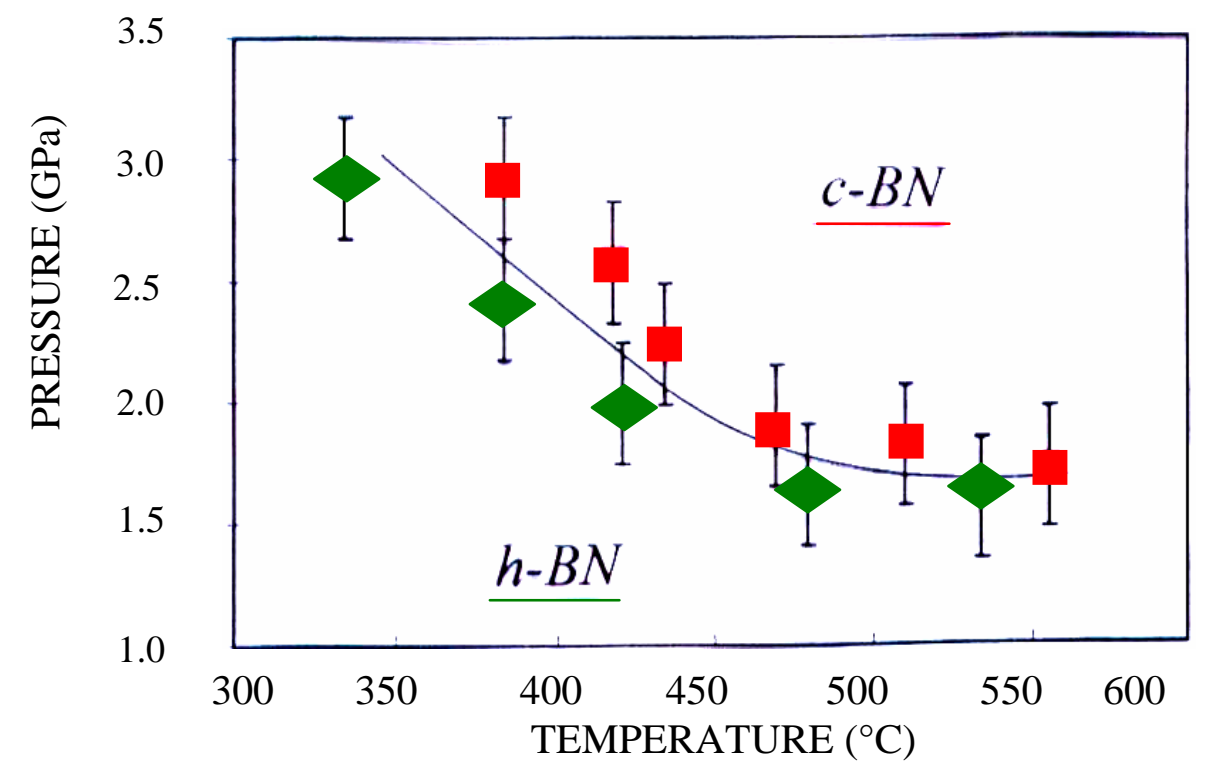

$\quad c-B N$

$>h-B N$

Fig. 4 

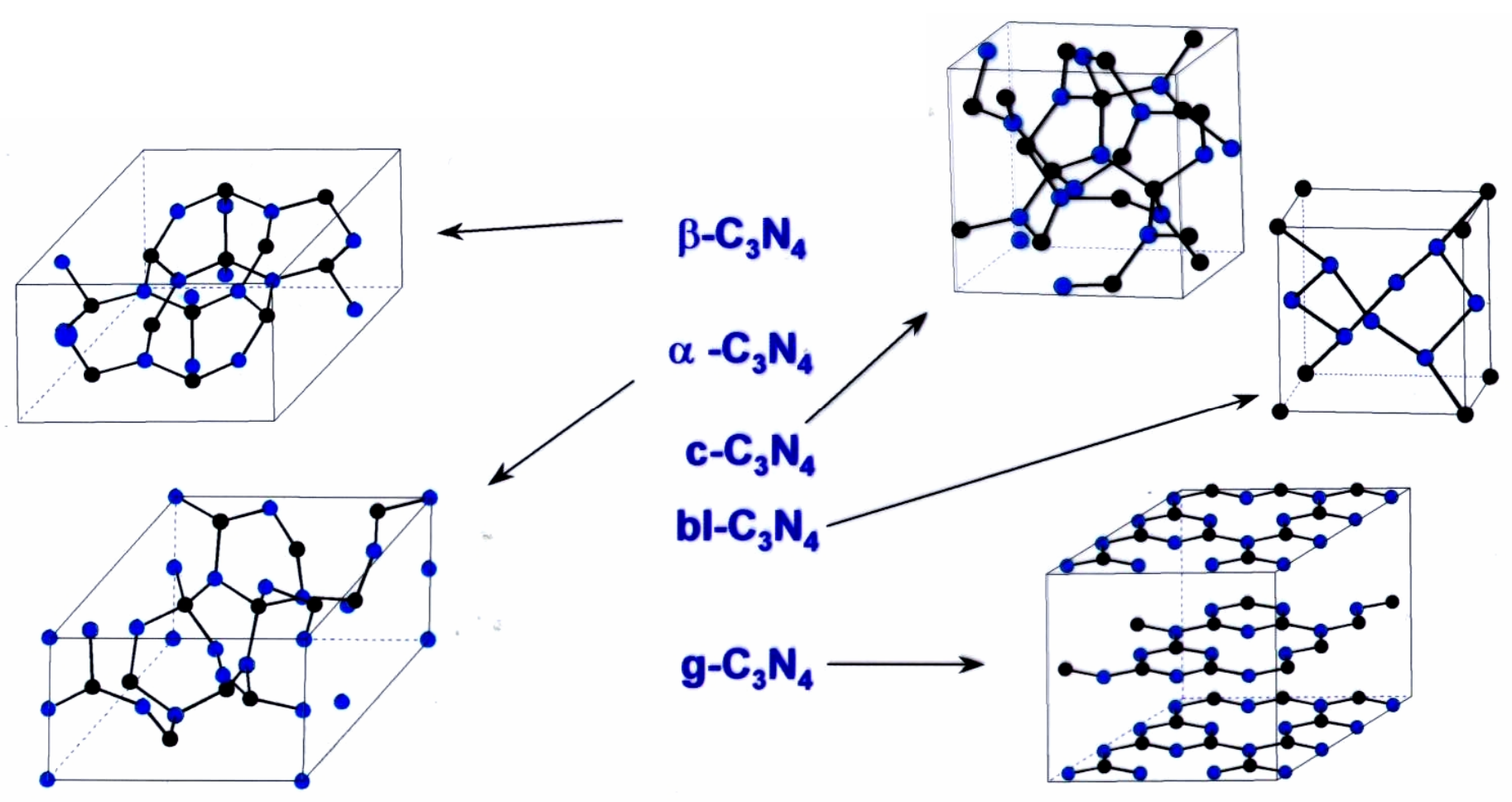

Fig. 5 